\title{
UNA REVALUACION DE LOS AÑOS 30 A PARTIR DE LA OBRA DE ANTONIO BERNI. De la experiencia surrealista a la formulación del nuevo realismo
}

\author{
GIII.IRMO AUGUISTOFANTONI *
}

En el periodo comprendido entre 1920 y $1930 \mathrm{el}$ arte argentino al igual que la literatura presenta uno de sus momentos más singulares. La aparición de nuevos aclores y formaciones así como de nuevas tendencias permiten hablar de un primer momento de vanguardia asociado de un modo recurrente a términos tales como renovación o revolución.(1)

Frente al carácter fulgurante de la déanda del 20 y a la multiplicidad de propuestas de la primera vanguardia -que condensa modelos estéticos que aharean desde los estilos posimpresionistas hasta las vueltas al orden pasando porlas vanguardias-la década del 30 es percibida como un registro más limitado en la que sólo se afianzan las fendencias del decenio anterior.(2)

Una mirada más a tenta sobre los actores y las producciones de los años 20 permitiría claborar una visión más matizada de la zona de vangua rdia así como un perfil más preciso sobre el carácter de la misma.(3) Por otra parte, si ponemos a foco la seric artística de la década del 30 es posible detectar junto a la permanencia de modalidades ligadas a la "escuela de París" la emergencia de nuevos episodios y rasgos que permitan trazar líneas divisorias. Casi simultáneamente a la aparición del surrealismo y la abstracción, dos vertientes que tienen un desarrollo más o menos fragmentario durante esos años, el núcleo más destacado de lo que podría ser llamado una producción emergente estaría dado por la propuesfa de un arte politizado de base realista potenciado por procedimientos modernos e inserto en prácticas de corte vanguardista.

Las exposiciones de Bernien 1932 y la de Del Prete en 1933, en las que se introducen las proposiciones del surrealismo y la abstracción respectivamente, pueden considerarse como los episodios que cierran el ciclo de manifestaciones públicas del movimiento de los años 20 y al mismo tiempo como la a pertura a los nuevos desa rrollos que ha rá eciosión

* Consejo de Investigaciones (CIUNR), Universidad Nacional de Rosario. 
a fines de la década del 30 y a comienzos del 40 . Mientras el abstraccionismo intermitente de Del Prete se convertirá en uno de los antecedentes más tempranos de las vanguardias concretas del 40 , el surrealismo berniano fecundará una de las experiencias estéticas más tensionadas políticamente. Nos referimos aquí a su propia formulación del "nuevo realismo" en la que confluyen los valores de la experiencia moderna con las utopías de la revolución.

\section{Formación europea y experiencia surrealista}

Si pensamos en las producciones más significativas de la década del 30 -surrealismo, nuevo realismo, muralismo, obras de formato "heroico", experiencias gráficas de intención política-éstas tuvieron como uno de sus principales protagonistas a la figura de Antonio Berni. Un autor que por su apertura a la modernidad y a las preocupaciones sociales tiene la singularidad de mostrar de un modo paradigmático los cambios de orientación estética e ideológicos entre la vanguardia de los años 20 y la vanguardia de los años 30. Será el nexo y al mismo tiempo el punto de fractura entre dos modalidades de vanguardia que, orientadas sucesivamente por la "utopía de lo nuevo" y por la "utopía de la revolución”, constituirán las dos fases de una primera emergencia de la modernidad estética en el arte argentino contemporáneo.

Iniciado en Rosario con maestros académicos de origen catalán-Buxadera, Fornels, Munné- completará su formación en Europa gracias a la obtención de becas que le permitieron permanecer en el viejo continente durante la segunda mitad de la década del 20. Unos pocos meses de residencia en Madrid, una prolongada estadía parisina, viajes breves por Italia, Bélgica y Hola nda le permiten ponerse simultáneamente en contacto con los movimientos renovadores y con la antigua tradición artística de occidente. La frecuentación de los talleres de André Lhote y de Othon Friesz, el deslumbramiento de los "ismos" y la admiración por los maestros ilalia nos del Quattrocento hacen de esta estadía europea una experiencia compartida por un conjunto de plásticos argentinos de la misma generación. Berni conformará con ellos el llamado Grupo de París cuyas obras se expondrán en Buenos Aires en una muestra de conjunto organizada por Butler. Realizada en Amigos del Arte hacia 1928, con obras de Spilimbergo, Badi, Butler, Basaldúa y Berni, significará para este último “...la demostración de fuerza de todo un equipo coherente, que venía a perfeccionar lo que ya Pettoruti había iniciado en 1924, individualmente...”.(4)

El escenario parisino -al que accede por el poderoso impacto de las declaraciones de Marinetti- era una especie de Babel lingüística en la que se combinan todas las nacionalidades y las tendencias. La avidez de Berni y su acelerado proceso de búsquedas formales lleva al arquitecto Prebisch, crítico vanguardista del periódico Martín Fierro, a hablar de "...un espíritu inquieto y dinámico...de intenciones divergentes...[y de]...un a fán exacerbado por apresar la idea fugitiva, para abandonarla luego en busca de nuevos interrogantes plásticos...".(5)

Lo que puede considerarse un itinera rio compartido no tarda rá en interrumpirse ante 
la aparición de nuevas expectativas que lo distancian del Grupo de París. En ese universo de intereses las tendencias más módicas de preocupación formalista ceden lugar a una estética radicalizada que profundiza los contenidos.(6)

La "nueva sensibilidad", equivalente castellano de l'esprit nouveau,(7) no llega a cubrir las necesidades de participación en cuestiones políticas y sociales en las que estaba implícita la construcción de un mundo a la luz de la "utopía revolucionaria".

Tras el impacto de la pintura fauve y luego de los ensayos cubistas sobreviene el descubrimiento del surrealismo.(8) Mientras otros creadores argentinos de vanguardia vieron en las primeras manifestaciones surrealistas sólo “...un propósito de escándalo y publicidad..."(9) para Berni se trataba de "...una visión nueva del arte y del mundo...la corriente que representaba a toda una juventud, su estado anímico y su situación interna después de terminada la primera guerra mundial...”.(10)

La frecuentación de los artistas, escritores y poetas surrealistas, el conocimiento de sus obras, la utilización de sus procedimientos y técnicas creativas significó no sólo un nuevo campo de experimentación sino una vía inédita para ingresar a la realidad.(11)

La amistad con Luis Aragón a partir de 1928 le llevó a frecuentar nuevos círculos(12) políticos e intelectuales como el Movimiento Antïmperialista y a compartir la tesis del compromiso del arte con la revolución y con las luchas de liberación de los pueblos.

Por otra parte, a las lecturas de los grandes escritores modernistas sobrevino el descubrimiento de Freud y luego, por su relación con los surrealistas, de Marx. La a mistad con el sociólogo Henri Lefebvre no fue ajena a las sugestiones que afianzaron sus posiciones estéticas, éticas e ideológicas y la relación con Paule Cazenave -quien fuera su primera esposa - estudiante de escultura y colaboradora de Henri Barbusse, lo vinculó fuertemente a una zona de preocupaciones intelectuales y políticas.

A diferencia de otros artistas argentinos residentes en París para quienes el rol del intelectual consistía solamente en pensar y crear,(13) Berni irá desarrolla ndo un núcleo de ideas que pondrá en práctica al regresar al país. Ideas que van a aflorar en la correspondencia que mantuvo con Aragón en torno a cuestiones -particularmente vigentes en los años 30-como las relaciones entre el arte y la política y las responsabilidades de los artistas y los intelectuales con la sociedad.

De todos modos, en este período de formación europea aunque adhiriera a alguna forma de activismo, Berni se ubicaba en lo que luego evocará como un campo puramente intelectual. A su regreso de Europa, en 1930, se encontra rá con una realidad excepcionalmente dura a la que percibe a partir de las nociones adquiridas, eso implica para él “...pasar del plano especulativo y abstracto, al plano concreto y real...".(14) Después de la muestra del Grupo de París, en la que se presentan los primeros resultados de la experiencia europea, será recién la exposición surrealista de 1932 en Amigos del Arte la que muestre de manera contundente las transformaciones más notables de la producción berniana de los últimos cuatro años. Hacia 1928 , Berni había realizado obras como $E l$ torero calvo o Toledo y el religioso que aunque no son específicamente surrealistas muestran una insinuación de lo extraño y de lo insólito que, según el propio autor, se incorporará más 
tarde a lo más significativo de su obra. Poco después de los autorretratos de 1929 , cuya atmósfera metafísica delata la gravitación de la pintura de De Chirico, Berni se encaminará, entre 1930 y 1932, a una inda gación del mundo onírico plas mada en una serie de pinturas y collages en una clave que hace pensar en Max Ernst.

Esta producción, impactante para su momento,(15) se torna altamente significativa si consideramos que las preferencias de los creadores de los años 20 por los maestros de la Escuela de París tuvo como contrapartida una actitud de distanciamiento frente a las manifestaciones más radicalizadas del vanguardismo histórico tales como ci dadaísmo, el surrealismo o las vanguardias rusas posrevolucionarias.

Las realizaciones de Berni no sólo marcan uno de los momentos culminantes de los impulsos modernistas iniciados en los años 20 , sino que constituyen un punto de inflexión en el que se gestan las líneas divergentes -aunque conectadas-del surrea lismo y del "nuevo realismo". La primera que cuenta con las figuras de Batlle Planas y de Pla nas Casas como sus creadores más consecuentes, será desarrollada a lo largo de la década del 30 , para alcanzar una amplia difusión con el Grupo Orión al final de la misma y a comienzos de los años 40.

Si se excluyen las insólitas "narraciones interiores" de Xul Solar, el surrealismo en la Argentina(16) tiene antecedentes muy precisos en algunos autores que como Berni, Spilimbergo y Raquel Forner desarrolla ron una obra en la órbita de la pintura metafísica para dedicarse luego a las variantes del arte social y políticamente comprometido.

Antonio Berni trasladó el extrañamiento de sus realizaciones surrea listas a los fondos de la épica cotidiana desplegada en sus gra ndes obras neorrealistas. Spilimbergo, autor de paisajes oníricos -1930-y de terrazas enigmáticas -1930/34-, se dedicará a la exaltación de tipos popula res por medio del despojamiento y la monumentalidad. Por su parte, Raquel Forner migra rá de las evocaciones del mundo clásico, y de las composiciones con estatuas de los primeros 30, a los dramas contemporáneos cuando estalle la guerra de España.

El crítico Damián Bayón,(17) al referirse al surrealismo en América Latina, ha planteado una problemática para el caso mexica no que se torna interesante para trazar las vinculaciones entre las principales líneas estéticas de los años 30 en el campo artístico argentino.

El surrealismo mexicano aparece según Bayón como válvula de escape al compromiso de una pintura basada más en supuestos éticos que estéticos. Esto es, que debido al aplastante predominio del muralismo, el que quería expresarse de un modo no comprometido a partir de los años 20 buscaba refugio en lo irracional. Podemos preguntarnos si más que una evasión no se trataría de una alternativa formal a las vertientes del arte comprometido con las cuales tendría puntos de articulación en torno a algún núcleo de ideas. En el caso argentino, la inclinación de algunos autores por el mundo onírico y sus posteriores desarrollos dentro del nuevo realismo, los realismos críticos o de una pintura de alegato con los recursos de lo imaginario, parece tener un complemento igualmente sugestivo. Algunos jóvenes,(18) enrolados a mediados de los años 30 en la realización de obras murales como Luis Barragán y Orlando Pierri, contribuirán, al final de los años 30 , 
a la proliferación de impulsos surrealistas en la esfera del Grupo Orión cuyas muestras se realizaron en 1939 y 1940 .

Así mismo, es igualmente llamativo que en el ámbito de la pintura de Rosario, los autores que como Juan Berlengieri y Leónidas Gambartes protagonizaran la emergencia de una temática fantástica o como López Armesto se ubicaron de un modo más ortodoxo en los márgenes del surrealismo, estuvieran vinculados desde conienzos de la década del 30 a la figura de Antonio Berni. Los ejemplos precedentes, hacen pensar que entre las tendencias del compromiso social y el surrealismo existió una vinculación flu ida a partir de la existencia de preocupaciones compartidas. Una preocupación sustancial por la libertad del hombre que, con sus matices ideológicos, sería resuelia en diversas claves visuales.

\section{El nuevo realismo}

La confluencia de los "ismos" que habían transformado el panora ma artístico europeo junto a las repercusiones de la Revolución rusa, convirtieron al campo artístico argentino de los años 20 en el escenario de una confrontación entre los partidarios del "arte por el arte" y los del "arte comprometido". Esta polémica, que afectó esencialmente a la literatura, tuvo de hecho su correlato en el sector de las artes plásticas a través de la existencia de distintos comportamientos y producciones.

Mientras los creadores relacionados con la franja de Boedo buscaban una legitimación a través de un sentido histórico y social para la actividad artística, la zona de vangua rdia se enrolaba en experiencias estéticas formalistas cuya autonomía era reivindicada por medio de la figura de lo nuevo. Será recién en los años 30 cuando la fundamentación social y política de las prácticas artísticas, enlazada a una coyuntura histórica crítica, encuentre su formulación en una clave vanguardista. De esta manera, el énfasis manifestado en los años 20 por las discusiones del proyecto estético de la vanguardia -en el que está en juego fundamentalmente la implementación de nuevos lenguajes formales-cederá lugar, a partir de los años 30 , a una revalorización de las problemáticas de tipo ideológico donde el rol del artista y la vinculación del arte con la sociedad ocupan un lugar privilegiado.(19)

El golpe de Estado de 1930 y la crisis económica generalizada con sus devastadoras secuelas en el campo social, a lo que se suma un coniexto internacional signado por el recrudecimiento de la lucha ideológica -avances del fascismo, avatares del comunismo, conformación de frentes populares, guerra española - llevó a los artistas e intelectuales a reorientar sus posiciones y a elaborar nuevas estrategias. Consolidada la ruptura con la tradición(20) para Berni será el momento de “...superar la etapa del exclusivo 'cómo pintar' para complementarla con el saber 'qué pintar', vale decir la preocupación por la forma unida a la preocupación por el contenido en indivisibles y equivalentes valores plásti$\cos . . . "(21)$

La emergencia del nuevo realismo berniano a partir de 1933 tendrá su primera formulación escrita en un artículo de la revista Forma de 1936. Este será el punto de partida 
de una sucesión de pequeños textos en los que se afirma reiterada mente un núcleo de ideas: la crítica a cierto tipo de modernidad estética basada en la pura especulación sobre las formas y los materiales del arte, la vinculación del artista y de sus producciones con los procesos históricos que impulsan los cambios y, dentro de un pensamiento finalista, el advenimiento de un nuevo orden que -a partir de prácticas artísticas y políticas de inspiración realistas- sustituirá a todo lo perimido.(22)

Si admitimos que la vanguardia del 20 virtualmente careció de tensión política y que sus transforma ciones en el campo del a rte -si exceptua mos a ciertas zonas más radicalizadastuvieron un carácter módico, la vanguardia de los 30 presentará un tipo de propuesta estética e ideológica fuertemente ruptural.

De un modo análogo a otros creadores que sintieron una particular tensión entre estética y política,(23) Berni consideró que las transformaciones formales no eran suficientes para provocar una verdadera revolución artística y que los creadores no debían perder el contacto con los procesos históricos que afectan a las dimensiones sociales y políticas de sus propias sociedades. Como correlato de estas concepciones sostendrá muy firmemente la necesidad de mantener la referencialidad en las obras de arte. El mantenimiento de las relaciones con el mundo objetivo estará en la base de sus preferencias estéticas, en la elección de sus repertorios formales y en el registro de sus diversas temáticas desde los años 30 en adelante. Por tal motivo Berni dirá años más tarde que

“...El Nuevo Realismo es un determinado concepto estético y un profundo y determinado tipo de humanismo. Esta escuela afirma lo humano pero simultáneamente, para contenerlo. afirma lo representativo realista como única y posible envoltura. Lo humano que más sugestiona en A mérica Latina, en este siglo que andamos, es el drama de los pueblos hundidos en el coloniaje, con su cadena de miseria y de incultura...".(24)

Diferenciado tanto de la modernidad formalista(25) como de la pedagngía social que enfrentaron a las franjas de artistas durante los años 20 , el nuevo realismo bernia no -en el que se mezclan la herencia de las vangua rdias históricas con los tópicos de la revoluciónse presentó como una propuesta políticamente apasionada y estéticamente provocativa. Las realizaciones de formato "heroico", las experiencias murales, las producciones gráficas de carácter político articuladas a la utilización de medios mecánicos, procedimientos de montaje y la apelación a nuevos soportes y vías de circulación hicieron de estas experiencias una particular forma de cuestionamiento del arte y de la realidad.

La presencia de Siqueiros a partir de comienzos de 1933, en cuyo transcurso protagonizó una serie de conferencias, intervenciones públicas y manifiestos, ejecutando finalmente un gran mural en la residencia de Natalio Botana con la colaboración de Spilimbergo, Castagnino, Lázaro y Berni,(26) definió a este último en sus presupuestos ideológicos, en la utilización de una metodología modernista y en la adopción de los formatos heroicos. Así mismo, está en la base de la polémica que Berni sostuvo con Siqueiros,(27) la adopción de los grandes formatos para una pintura transportable como 
alternativa a un arte mural escasamente viable en el contexto político y social argentino. Concluida la etapa de experimentaciones y de actualizaciones virtualmente replegadas a los confines de lo estético, Berni se abocará al relevamiento de los aspectos más inquietantes de su propia cotidia neidad en el marco de las problemáticas contemporáneas. Las producciones de este período(28) que oscilan entre el retrato monumentalizado - $\mathrm{La}$ mujer del Sweater rojo- y el drama contemporáneo-Medianoche en el mundo-pasando por la épica cotidiana-Manifestación y Desocupación-y la crónica periodística-Hombre herido- hacen pensar en la recuperación de las verdades sociales capaces de convertir a la obra en un espejo de la realidad pa ra poder operar sobre la misma. Por estas razones Berni planteará que

"en el nuevo realismo que se perfila en nuestro medio, el tejido de la acción es lo más importante, porque no es sólo imitación de los seres y cosas; es también, imitación de sus actividades, su vida, sus ideas y desgracias. El nuevo realismo no es una simple retórica o una declaración sin fondo ni objetividad; por el contrario es el espejo subjetivo de la gran realidad espiritual, social, política y económica de nuestro siglo...".(29)

Deudor de sugestiones estéticas diversas -surrealismo, pintura meta física, realismos alemanes, muralismo mexicano- técnicamente experimental y de fuerte tensión moderna por sus percepciones y su intencionalidad, el nuevo realismo significó también la emergencia de nuevos protagonistas. Tanto su formulación como sus primeras realizaciones fueron el resultado de prácticas experimentales de artistas jóvenes políticamente motivados que liderados por Berni actuaban en la ciudad de Rosario.(30) La dimensión sociopolítica como fundamento de las prácticas a rtísticas al estar mediada por intenciones renovadoras no sofocó en este caso la posibilidad de rupturas estéticas. Por el contrario, la apelación a un elenco de temas como registro de los problemas de la sociedad se articuló con constelaciones formales en las que una base realista se potenció con procedimientos vanguardistas y los tópicos de la modernidad.

La adopción por parte de Berni de un realismo heterodoxo(31) en el que intencionalmente se superponen representaciones detalladas, distorsiones expresionistas y ciertos climas que remiten a sugestiones metafísicas o surrealistas(32) nos lleva a repensar ciertas nociones sobre el vanguardismo y lo moderno en relación a las cuales el nuevo realismo ocupe su lugar.

En primer término, frente a las teleologías de lo moderno abogamos por visiones más complejas, donde el cuestionamiento de la representación y la adopción de nuevas formas y procedimientos ligados en muchos casos a la elaboración de lenguajes abstractos no excluya la consideración de ciertos pliegues y tensiones. Si como plantea Marchan Fiz(33) la modernidad no se desliza linealmente, sino a través de un recorrido discontinuo y fragmenta rio, el neorrealismo representa en nuestro caso uno de esos momentos de tensión en los que ciertas nostalgias clásicas se enlazan con preocupaciones estéticas y políticas contemporáneas. En segundo término, el tema nos enfrenta a diversas concepciones de la 
vanguardia. La misma, no designaría en este caso a un reagrupamiento de artistas preocupados sola mente por llevar adelante innovaciones estéticas sino que involucra a una forma de cambio cultural cuyas rupturas ma nifiestan una intencionalidad más específica. Esto es, nos encontra mos a nte un tipo de objetos artísticos producidos de una determinada manera y de acuerdo a ciertos procedimientos. Objetos que al circular por nuevos espacios -en los que son percibidos por una clase particular de espectadores-cumplirán roles que hacen pensar en la intención de reintegrar el arte a la vida y en la erosión de la noción de autonomía.(34)

La producción de cuadros realistas a escala mural -definidos por Berni como pintura transportable- realizados a partir de apuntes fotográficos(35) con medios mecánicos y materiales industriales, a menudo a varias manos; cuadros concebidos para ser emplazados en espacios públicos y en situaciones de conflicto para que actúen como elementos de cohesión y agitación política y social (36) plantean la existencia de un tipo de objetos artísticos y de prácticas que vulneran la noción de autonomía del arte. Un tipo de producciones y de prácticas para las cuales la designación genérica de "realismos sociales" no da cuenta de su naturaleza vanguardista que la separa de otras propuestas tensionadas ideológicamente y que la sola aplicación del término nuevo resulta generalizado e inespecífico en relación con otras formas de modernismo y líneas de vanguardia de preocupación más formalista.

\section{NO'TAS}

(1) CORDOVA TTURBURU, C., "La renovación Martinfierrista", Lyra, N¹5, Buenos Aires, 1958 -segundo número extraordinario de 1958- O del mismo autor. La Revolución Martinfierrista. Ediciones Culturales Argentinas, Buenos Aires, 1962.

(2) Este tipo de valoración de los años 30 aparece en PIROVANO, I., PAZ, J.C., "Buenos Aires 1929". en Argentina en el Arte, N $N^{2} 14$, Viscontea, Buenos Aires, 1967. El mismo planteo es retomado por HABER. A., "Vanguardia y tradición", en AA.VV., La pintura argentina, CEAL. Buenos Aires, 1975. Una visión diferente. en la medida que revaloriza a la vanguardia de los años 30, aparece en el Marco Histórico propuesto por Martha Nanni, en NANNI, M. et al., Arte Argentino Contemporáneo, Ameris, Madrid, 1979.

(3) Véase nuestro documento de trabajo, Reflexiones en torno a la vanguardia artística de loss años 20 . Rosario. 1991.

(4) BERNI, A., "Berni: Cómo desarrollar la realidad", en Primera Plana, Buenos Aires, ahril. 1965, págs. 40-44.

(5) PREBISCH, A., "El Anti-Rinoceronte", en Martín Fierro: las primeras vanguardias, Galeria Ruth Benzacar. Buenos Aires, 1983.

(6) "Despues del impresionismo, parecía que la preocupación de los nuevos artistas argentinos se orientaba dentro de una línea única cada día más ajena a la temática, o más bien dicho, con la temática tomada como pretexto para realizar la piatura y sólo la pintura".

"Pero esta línea se bifurca pronto, la exposición de Berni de neto contenido surrealista realizada en Amigos del Arte en 1932, es el arranque de otra rama del árbol artístico argentino"....."Otra rama surge de ésta alimentada por el acaecer social, sin perder por ello las anteriores savias de la modernidad formal. Fue una corriente particular del arte latinoamericano cuyo foco principal se encendió en México con los grandes muralistas...". BERNI. A., "Semblanza del arte argentino desde 1900 a 1950", en NANNI, M. et al., op. cit., págs. 9-13.

(7) Cfr. SCHWARTZ, J., Las vanguardias latinoamericanas. Textos programáticos y críticos, Cátedra, Madrid, 1991. 
(8) "Había hecho ensayos cubistas, pero no me sentía cómodo: el cubismo ya era viejo entonces...Por primera vez, junto al surrealismo me sentí contemporáneo, ya no se trataba de ir descubriendo un mundo de fenómenos estéticos para ponerme al día, sino de encontrarme conmigo mismo". BERNI. A., "Berni: Cómo desarrollar...", op. cit., pág. 41.

(9) BUTLER, H., La pintura y mi tiempo, Sudamericana, Buenos Aires, 1966, pág. 83.

(10) Berni, en VIÑALS, J., Bermi, Imagen, Buenos Aires, 1976, págs. 40-41.

(11) "...mi amigo Aragón -a quien considero un maestro literario-y yo seguimos, en nuestras respectivas artes, una ruta paralela: el ingreso a la realidad por vía del surrealismo, del que nunca nos hemos apartado del todo". BERNI, A., en "Berni: Cómo desarrollar...", op. cit., pág. 41.

(12) "...por los años 27, 28, era frecuente que nos encontráramos en el café ' $\mathrm{a}$ a Rotonda' los amigos argentinos que estaban, como yo, haciendo su experiencia europea: Badi. Butler. Basaldúa. Spilimhergo. Bigatti. Raquel Forner y otros que no eran artistas. Esa era una mesa bastante seria. en el sentido de que era gente de una vida muy melódica...ese grupo tenia preponderantemente muy activos intereses culturales o intelectuales. y ese era el epicentro de sus preocupaciones y su razón principal de permanencia en el viejo mundo...había otro grupo más loco, más bohemio, más interesado en la vida nocturna...era más beterogéneo: no había tantos artistas, ni escritores, ni intelectuales. Alguno del otro grupo, Spilimbergo, por ejemplo, se integra ba también...el tercer grupo de amigos en Europa...fue realmente el que más me motivó y más me enriqueció en todos los órdenes...era tan serio y riguroso como el primero y tan funambulesco como el segundo...Eramos. la mayoria, artistas, intelectuales, estudiantes. Toda gente del que hoy se llama Tercer Mundo. Ese era como un foro internacional, no institucionalizado, desde luego, pero con un común objetivo: la lucha contra el imperialismo. En los otros grupos el tema político era secundario... Este tercer grupo estaba en la praxis; se publicaba un periódico para las minorías asiáticas. africanas, latinoamericanas y había que distribuirio; se redactaban manifiestos: se preparaban colaboraciones il ustradas para diarios y revistas; era una verdadera militancia...”. Berni. en VIN̄ALS. J., op. cit., págs. 47-49.

(13) BUTTLER, H., op. cit., pág. 109.

(14) Berni, en VIÑALS, J., op. cit., pág. 44.

(15) “...el público no estaba preparado para aceptar la forma y el espíritu de esas obras, ni tampoco la crítica oficial que las rechazó rohundamente. Por primera vez, en Buenos Aires, se hacía y se mostraba 'collage' como los de 'Susana y el viejo' o 'La tranquilidad de los barrios aristocráticos'. Años después de esta exposición surgieron nuevos surrealistas, ortodoxos unos, meramente formales otros, pero yo no los acompañé, estaha preocupado ya por otras disciplinas estéticas...". BERNI, A., Texo del Catálogo Berni. El surrealismo 1928-32. Galería El Taller, Buenos Aires, noviembre, 1969.

(16) Cfr. PEI I EGRINI, A.. Texo del Catálogo Surrealismo en la Argentina. Centro de Artes Visuales del Instituto Di Tella, Buenos Aires, junio, 1967.

(17) BAYON, D., Aventura Plástica de Hispanoamérica, FCE, México, 1974.

(18) Un artículo periodístico comenta la realización por parte de Mauricio Lasansky y Luis Barragán, ambos jóvenes artistas de veintiún ańos, de una obra mural que cubre cuarenta y dos metros cuadrados de superficie en la casa del lng. Pellegrini en Villa Ballester. En el mismo se plantea, como contrapartida crítica a la imagen bucólica de los pintores que viajan al sur argentino, la "...tragedia de la vida humana en esas regiones..." . El mural se realiza sin boceto anterior y sin plan preconcebido "...de esta manera se rehuye todo academicismo, destruyendo toda posibilidad de normas clásicas. En cuanto a la técnica del procedimiento, ella está hecha hasada en forma directa con la de Rivera y Orozco...". Esto es, un arte monumental que, en opinión de los autores debe "ser socialmente interpretado". Estos artistas plantean como proyecto la búsqueda de "iemas netamente argentinos" y se proponen dirigirse al Norte "para observar la vida de los obreros de los ingenios tucumanos e interpretaria mediante una gran pintura mural" que sin dudas se presenta como distinta del tipismo y el costumbrismo tradicional. Colaboraron en la ejecución Orlando Pierri y Eduardo Bentre. En un fresco de grandes proporciones pintan el drama de la vida patagónica. Es una obra de Lasansky y Barragán. Crítica, 16/10/35:

(19) "...la muy grave situación del país me impone seguramente un desafio nuevo y tal vez también una acelerada toma de conciencia; pero, al mismo tiempo una reafirmación de los conceptos. acerca de las relaciones del artista con la sociedad. Todo eso, naturalmente, revoluciona y le plantea al artista nuevos problemas, mayores responsabilidades y exigencias superiores...El artista está obligado a vivir con los ojos abiertos y, en ese momento, la dictadura, la desocupación, la miseria, las huelgas, las luchas obreras, el hambre, las ollas populares, eran una 
tremenda realidad que rompía los ojos...". Berni, en VIN̈ALS, op. cit., pág. 56.

(20) Cfr. VERANI, H., Las vanguardias Literarias en Hispanoa mérica (Manifiestos, Proclamas y otros escrilos), FCE, MÉxico, 1990.

(21) BERNI, A., Teaco del Catálogo de la muestra Antonio Berni expone 22 obras en la Galería Viau, Buenos Aires, 18 al 30 de agosto, 1952.

(22) "...siempre el hombre, en su permaneate necesidad de expresar gráficamente sus sensaciones ha tenido en la naturaleza y en la vida social los elementos objetivos que componían su mundo dramático. Sólo en el siglo XX. en un vuelo de Icaro, el pintor se aleja del mundo real para alcanzar el otro quimérico de las puras formas y colores. Ya conocemos el resul tado de esta aspiración. Las alas de lcaro se quemaron, y en su precipitado descenso, por ley de gravedad. vuelto al mundo del que se había querido desprender...El verdadero artista y el verdadero arle de un pueblo es aquel que abre nuevos caminos impulsados por las cambiantes condiciones ohjetivas...Un nuevo orden, una nueva disciplina. apoyados por una nueva crítica inspirada en la realidad concrela que vivimos debe sustituir todo to caduco que hoy soportamos...". BERNI. A., "El Nuevo Realismo". en Forma. Revista de la Sociedad Argentina de Artistas Plásticos, № 1, agosıo, 1936, págs. 10-14.

(23) Cfr. SCHWARTZ, J., "Estética vanguardista y revolución", op. cit.

(24) BERNI, A., Texto del Catálogo de la muestra Antonio Berni.... op. cit.

(25) "No se es moderno ni creador imitando tal o cual especie de creación o modernidad caduca; no se sigue el ejemplo de Cézanne o Picasso imitándolos en sus maneras de pintar, sino interpretando, como ellos lo hicieron en su tiempo, los nuevos fenómenos de la realidad, las nuevas leyes que influencian el espíritu y la originalidad del momento en que se vive. El verdadero artista y el verdadero arte de un pueblo es aquel que abre nuevos caminos impuisados por las cambiantes condiciones objetivas; en cambio dejan de serlo los que pasan y obran según el cliché establecido, aferrándose a formas pasadas y caducas, que no obedecen a ninguna realidad artística ni social". BERNI, A., "El Nuevo Realismo", en Ars. Todas las Artes, No2, Buenos Aires, 2 (7-8): 6-8, febrero/marzo, 1941, págs. 6 y 8.

(26) Cfr. el manifiesto Qué es 'Ejercicio Plástico' y cómo fue realizado. Buenos Aires. diciembre. 1933. firmado por el equipo Poligráfico Ejecutor: David Alfaro Siqueiros. Lino Eneas Spilimbergo, Enrique I ázaro, Juan C. Castagnino y Antonio Berni.

(27) Cfr. BERNI, A., "Siqueiros y el arte de masas", en Nueva Revista. Buenos Aires, enero, 1935.

(28) Cfr. NANNI. M., Texto del catálogo de la muestra Antonio Berni. Obra pictórica. 1922-1981, Museo Nacional de Bellas Artes, Buenos Aires, junio/julio, 1984.

(29) BERNI, A., en Ars. Todas las Artes, op. cit., pág. 8.

(30) "Cuando llegué(de Europa) yo no me quedé en Buenos Aires, me fui a Rosario y me metí en actividades culturales que tenían un sentido de lucha y esclarecimiento. Organicé la 'Mutualidad de Estudiantes y Artistas Plásticos' que tuvo un peso muy grande en la formación de muchos jóvenes...el Nuevo Realismo surgió en ese momento; lo fundamos con un grupo de compañeros que tenían las mismas preocupaciones que yo. Si bien en el orden estético ellos no tenían la preparación que yo había adquirido durante mi estadía europea, en el orden ideológico tenían una posición definida y coincidíamos. en realidad, yo, para muchos de ellos, tenía casi el rango de maestro; no en el sentido del hombre que está en el pedestal, sino simplemente en reconocimiento de que yo traía una experiencia en el orden artístico que ellos no babían podido hacer en el país y que yo me empeñaba en transmitiries. En el otro plano, en el ideológico y político, ellos ya habían madurado; en su mayoría eran jóvenes bijos de intelectuales o de trabajadores con una trayectoria en las luchas políticas y sindicales...". Berni, en VIÑALS, J., op. cit., págs. 57-58.

(31) "Para mí, el realismo era una suerte de denuncia pero que implicaba libertad expresiva amplia en cuanto a los medios con que se manifestaba. No hacía hi ncapié sobre el tipo de imagen que se debía de emplear o el estilo". Berni, en MONZON, H. y SZPUNBERG, A., "Antonio Berni y su típica”, en La Opinión Cultural, Buenos Aires. 10/08/75, pág. 2.

(32) 'La alta expresividad del mundo exterior se difunde en sus elementos formales: mis dones de pintor deben equivalerse con el contenido de mis vivencias, de lo que veo y siento. Comprendo que aquel fue un período muy analítico, pero no debe creerse que me plegaba ciegamente a la realidad objetiva; también exploré la imaginación, nunca dejé de ser surrealista del rodo...". BERNI, A., en "Berni. Cómo desarrollar...", op. cit., pág. 42.

(33) Cfr. MARCHAN F1Z, S., Contaminaciones figurativas. Imágenes de la arquitectura y la ciudad como figuras 
de lo moderno, Alianza, Madrid, 1986.

(34) Cfr. BURGUER, P., Teoria de la vanguardia, Peninsula, Barcelona, 1987.

(35)"... siempre me ha interesado mucho la documentación folografica y la tre empieado en toda mi obra, sea hecha directamente por mí, sea sacada de diarios y revistas, en casi toda mi trayectoria he usado. mezclándolos o no, el dibujo directo y la fotografía...". Berni, en VINA.ALS, J. op. cit, pág. 32.

(36) "En esa epoca yo pensaba -y lo sigo sosteniendo- que la función del intelectual es esclarecer las conciencias... ya en esa vieja epoca se discutia lo del compromiso... El asunto es saber llevar el arte al plano de ia oficacia, de la contundencia. Es entonces cuando la protesta se vueive peligrosa y es cercada por el silencio o ipor qué no? ta mbién por la represión. En 1933 hice para un sindicato de oficios varios de Rosario dos pinturas grandes. Recuerdo que un día cayó por ahí la polićáa y puso fin a tanta plástica... En esa tpoca usé mucho el collage en hase al folomontaje, principaimente en trabajos que hice para algunas instituciones políticas que ya han desaparecido...". Berni, en MONZON. H. y SZPUNBERG, A., op. cit.. pág. 2. 